\title{
And out into the world they go ... research on the international stage
}

The Leader in the July/August issue of the South African Journal of Science reflected briefly on the loss of senior university managers who have left the local system to take up leading positions in universities elsewhere in the world. The Leader mentioned that this has also been true of scientists and scholars - and in this Leader we reflect on a different aspect of internationalisation - changes in patterns of research output and cooperation.

To do so, the Leader relies substantially on the June 2018 issue of SciBytes ${ }^{1}$, published by the DST-NRF Centre of Excellence in Scientometrics and Science, Technology and Innovation Policy (SciSTIP). The authors of the June issue, Prof. Johann Mouton and Dr Jaco Blanckenberg, have granted permission to draw on their work here.

In making their calculations, the authors make use of the Web of Science database, and confine their assessment to South Africa's publications in two categories: 'articles' and 'review articles'. This means that they exclude documents such as books, book chapters and conference proceedings in their counts which are based on three indicators: (1) publication output, (2) international collaboration and (3) citation visibility or impact.

In the 17-year period between 2000 and 2016, three major shifts have taken place in the nature of South African scientific publishing. First, research publications have not just increased (as might be expected) but increased significantly. Secondly, South African scientists have come to collaborate considerably more frequently with scientists and scholars internationally than before. Thirdly, the growth in South Africa's publication output has taken place at the same time as there has been an increase in the visibility of our scientific papers.

South Africa's publication output in the Web of Science has increased from 3668 publications in 2000 to 15550 in 2016. This increase translates into an average annual growth rate of $2.9 \%$. This growth has been such that South Africa's share of world output more than doubled from $0.4 \%$ in 2000 to $0.91 \%$ in 2016 . Not surprisingly, these results have translated into an improved position when comparing South Africa with other countries. As far as country rank is concerned, South Africa has improved its ranking in the world from position number 34 in 2000 to 28 in 2016, despite obvious competition.

It is standard bibliometric practice to measure research collaboration by looking at patterns of co-authorship in scientific papers. The SciBytes report followed the same practice and specifically distinguished between four categories of collaboration:

- No collaboration (either single-authored articles or single-institution authorship)

- National collaboration (multiple authors from more than one institution in South Africa)

- International collaboration with scientists from African countries only

- International collaboration with scientists from countries outside of Africa

The results (Figure 1) show a clear trend towards more international collaboration. This in itself is a desirable development as increased international collaboration often translates into higher citation impact, increases in networks and access to more funding opportunities.

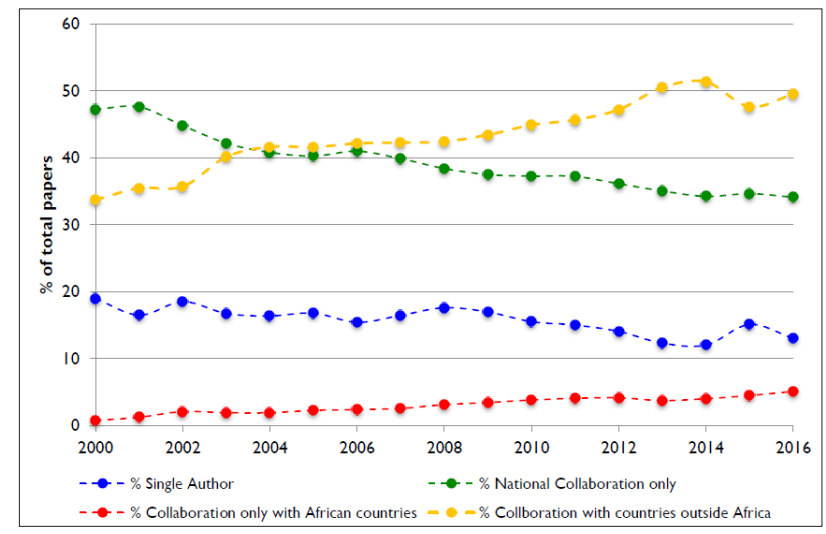

Source: Mouton and Blanckenberg

Figure 1: South Africa's publication collaboration profile (2000-2016).

In 2000, about a third of South Africa's papers involved co-authorship with at least one foreign author. By 2016, this proportion had increased to $50 \%$. The increase in international collaboration has occurred at the 'expense' of national collaboration (which declined from 47\% to $34 \%$ over the same period) as well as a clear decline in singleauthored publications. There is a small, but steady, trend of increasing collaboration with scientists and scholars in the rest of Africa: this proportion increased from a near-zero base in 2000 to 5\% in 2016.

As for the third change, an increase in scientific output does not necessarily imply that such output is recognised by other scientists working in the same fields. So the question was asked as to whether or not the substantial growth in South Africa's production of scientific papers translated to an increased visibility amongst scientists.

The visibility of science is partially captured by looking at the number of times research publications are cited in the publications of other researchers. Citation practices were normalised in order to allow for comparison. The resulting analyses show that the citation impact of South Africa's scientific papers has increased steadily from 0.8 in 2000 to 1.1 in 2016. This is a very positive result as a score of above 1 means that South Africa's papers are, on average, being cited slightly more than all the papers in the fields in which we publish.

In short - the 17-year period saw a noteworthy increase in research publications; there has been a significant increase in internationally cooperative research and publishing; and papers involving South African scientists are being cited more frequently (as might be expected as a result of international cooperation) than previously. There is much to be pleased about and to support going forward.

\section{Reference}

1. Mouton J, Blanckenberg J. How well is South African science doing? SciByte@SciSTIP. 2018 June No 2 [cited 2018 Aug 14]. Available from: http://www0.sun.ac.za/scistip/wp-content/uploads/2018/06/SciBytes@ SciSTIP_02.pdf 